\title{
Removal of Manganese and Iron from Groundwater in the Presence of Hydrogen Sulfide and Ammonia
}

\author{
Milka M. Vidović*, Ivana S. Trajković, Saša S. Rogan, Vladimir M. Petrović, Sanja Z. Jovanić \\ Department of Ecology and Technoeconomics, The Institute of Chemistry, Technology and Metallurgy, \\ University of Belgrade, Belgrade, Serbia \\ Email: ${ }^{*}$ mivibgd@yahoo.com
}

Received 11 November 2014; revised 10 December 2014; accepted 25 December 2014

Copyright (C) 2014 by authors and Scientific Research Publishing Inc.

This work is licensed under the Creative Commons Attribution International License (CC BY).

http://creativecommons.org/licenses/by/4.0/

c) (i) Open Access

\begin{abstract}
Presence of iron and manganese in water not only affects the organoleptic properties of water, but also can cause a number of problems in drinking water treatments. Their removal in drinking water preparation processes becomes more complicated in the presence of hydrogen sulfide and ammonia in water. There are certain commercialized products at the market that are used for removal of manganese, iron and ammonia, but it is of crucial importance to establish an appropriate order of removal in the technological process during drinking water treatment. Through the various combinations of commercialized filtration media, the removal of iron, manganese, hydrogen sulfide and ammonia, was being examined and on the basis of obtained results their effectiveness was estimated. Research results have shown that hydrogen sulfide is pollutant that causes problems during the adsorption in removing manganes. Ammonia, which is bonded to hydrogen sulphide influences the volume of treated water when it comes to removing the iron and manganese. Decrease in the concentration of hydrogen sulfide at the entrance to Filtersorb FMH for four times, has led to an increase in the volume of treated water in the amount of two times, followed by the breakthrough point of concentration of manganese. For complete usage capacity of commercialized products for the removal of these pollutants, finding their mutual bond in compounds which are present in the water, is of the importance.
\end{abstract}

\section{Keywords}

Hydrogen Sulfide, Ammonia, Iron, Manganese, Adsorption

\footnotetext{
"Corresponding author.
} 


\section{Introduction}

The presence of iron, manganese, hydrogen sulfide and ammonia in ground and surface waters, can cause a number of problems that are related to the health safety of water. Iron and manganese are colourless in the dissolved form, but in contact with air turn into an insoluble form, and their deposition causes reddish or brownblack colour of the water, metallic taste and unpleasant odour, which impairs the organoleptic properties of water and may promote the growth of certain types of chlorine tolerant micro-organisms [1]-[3]. Low concentrations of iron and manganese in water are not considered as a health risk, on the contrary, they are essential, and for this reason they are usually designated as secondary or aesthetic contaminants. However, during prolonged consumption of increased concentrations of manganese in drinking water, it has been found that manganese can damage the respiratory and central nervous system and DNA damage. Increased concentrations of manganese in drinking water can be toxic for the embryo and fetus [4]. The presence of ammonia in the water supply system may cause nitrogenous oxygen demand, and the occurrence of eutrophication, due to uncontrolled algae growth. The appearance of hydrogen sulfide in water creates an unpleasant odour of water, and due to its toxicity, its presence in drinking water is limited [5]. Due to the pronounced toxicity, hydrogen sulfide is undesirable in the drinking water, and if it is present, it is necessary to be removed [6].

Iron and manganese dissolved in water are usually in the form of bicarbonate, sulfate, or hydroxide, and may also be affiliated to a specific organic substance [7]. The mentioned parameters can occur in the water in dissolved form (as $\mathrm{Fe}^{2+}$ and $\mathrm{Mn}^{2+}$ ions), in the form of particles (as $\mathrm{Fe}^{3+}$ and $\mathrm{Mn}^{4+}$ ions) as well as colloids (in the form of small particles that are difficult to be precipitated, and filtered). Regardless of the fact that manganese can be present in water both in dissolved form and in suspended form, only the total manganese is usually determined [4]. The prevalence of certain forms is conditioned by the values of $\mathrm{pH}$, Eh and temperature [8]. Depending on the $\mathrm{pH}$ value, ammonia can be found in water either in the form of $\mathrm{NH}_{4}^{+}$ions or in the form of $\mathrm{NH}_{3}$ at high $\mathrm{pH}$ values [9]. It is important to emphasize that the ammonia in drinking water treatment should be removed prior to disinfection with chlorine, in order to prevent the formation of chloramine, which was confirmed as carcinogens [10] [11]. Also, depending on the $\mathrm{pH}$ value, the hydrogen sulfide is available, either in the form of $\mathrm{HS}^{-}$ions, at the $\mathrm{pH}$ above 6.9, or as $\mathrm{H}_{2} \mathrm{~S}$ at the $\mathrm{pH}$ below 6.9.

Recommended concentrations by European Economic Community (EEC) for drinking water are: for iron 0.2 $\mathrm{mg} / \mathrm{L}$, for manganese $0.05 \mathrm{mg} / \mathrm{L}$ and for ammonia $0.5 \mathrm{mg} / \mathrm{L}$ [12]. Regulation on Hygienic Quality of Drinking Water in Serbia recommends Maximum Allowable Concentration (MAC) in drinking water: for iron $0.3 \mathrm{mg} / \mathrm{L}$, for manganese $0.05 \mathrm{mg} / \mathrm{L}$ and for ammonia $0.1 \mathrm{mg} / \mathrm{L}$ [13].

Pollutants such as ammonia, iron and manganese can be removed from the water by chemical or biological means. Physico-chemical oxidation of ammonia is carried out by ion exchange processes, microfiltration, reverse osmosis, "air stripping" processes or by using a strong oxidizing agents. Oxidation of the ammonia is achieved by the simple aeration. At neutral $\mathrm{pH}$ values, the oxidation of $\mathrm{Mn}^{2+}$ to $\mathrm{Mn}^{4+}$ represents a slow process [14], whereas the efficiency of the iron oxidation is much higher and for these reasons, manganese can't be removed by simple aeration and sedimentation. Taking into account that the dissolved manganese oxidizes more slowly than iron, its removal from water is more difficult. Manganese is usually present in water as $\mathrm{Mn}^{2+}$ ion, and its salts have higher level of solubility in acidic than in alkaline environment [8]. Methods for the removal of manganese are based on the oxidation of the Mn (II) to the insoluble Mn (IV), in the presence of strong oxidants such as $\mathrm{KMnO}_{4}, \mathrm{O}_{3}, \mathrm{ClO}^{-}, \mathrm{ClO}_{2}$. Manganese greensand is one of the most common medium in use for removing of iron and manganese, through pressure filtration.

Commercial products that can be found on the market for removal of iron, manganese and hydrogen sulfide are: Greensand, Greensand Plus and Filtersorb FMH. The basis of Greensand makes glauconite, whereas the basis of Greensand plus is siliceous sand, while the basis of Filtersorb FMH is dolomite, which are covered with manganese dioxide as a catalyst in oxidation-reduction reactions of iron, manganese and hydrogen sulfide. The optimum $\mathrm{pH}$ value for the operation of the filter medium is within the range from 6.2 to 8.8. Regeneration or renewal of such media is carried out by continuous or discontinuous dosing of potassium permanganate. The removing capacity of the Filtersorb FMH separately are: for iron $3000 \mathrm{mg} / \mathrm{L}$, for manganese $1500 \mathrm{mg} / \mathrm{L}$, and for hydrogen sulfide $500 \mathrm{mg} / \mathrm{L}$ [15].

For the removal of ammonia the following media are available on the market: ion exchange resins, natural zeolite-clinoptilolite (alumino-silicate mineral comprising a replaceable cations based on the alkali and alkaline earth metal: Na, K, Ca and Mg), and a synthetic zeolite-Crystal Right ${ }^{\mathrm{TM}}$ (CWG GmbH, Mannheim, Ger- 
many). Benefits of zeolite compared to ion exchange resins are: efficient removal of ammonia at lower temperatures, compact size (which facilitate maintainance) and selectivity to ammonia. Only at $\mathrm{pH}<8.0$ in ammonium in ionic form may be removed, and the optimal ion exchange is carried out at a $\mathrm{pH} \leq 7.0$. During the reaction of ion exchange, $\mathrm{Na}^{+}$ion is replaced with $\mathrm{NH}_{4}^{+}$ion, causing an increase in the concentration of sodium in the aqueous solution. The capacity of the resin depends on the presence of other cations in the aqueous phase, and the initial concentration of ammonia [16].

Simultaneous biological removal of these three pollutants is a very complex process, mainly due to the different values of the redox potential, which are required for their oxidation. Researchers drew the conclusion [17]-[19], that in raw water containing ammonia, prior to biological removal of manganese the complete nitrification is necessary, due to the indispensable evolution of redox potential.

However, this scientific area requires more thorough research of pollutants removal in the presence of hydrogen sulfide. Sequence of pollutants removal can be significantly influenced by the presence of ions $\mathrm{HS}^{-}$, which has a lower oxidation potential compared to manganese, and higher comparing to iron and ammonia.

For these reasons, there were examined the possibilities of removing these pollutants from the water and followed by their removal efficiency. In particular, the efficiency of hydrogen sulfide and ammonia removal were examined as well as their individual impact on the removing of iron and manganese.

\section{Materials and Methods}

The performed research is carried out on a pilot plant with capacity of $0.01 \mathrm{~m}^{3} / \mathrm{h}$, in order to define the process of purification of ground water from wells in the Fruska Gora region (Pannonian Plain, North Serbia), which is characterized by a specific chemical composition. The chemical composition of this water is characterized by increased levels of hydrogen sulfide, ammonia, iron and manganese. The processes of removal of ammonia, iron and manganese and hydrogen sulfide were carried out on a pilot plant, which was consisted of a column of plexiglas, with a continuous flow of raw water (Figure 1).

Water samples were taken at the entrance of each column and behind each of the columns, for the purpose of determining the concentration of the individual parameters.

In the first case (A on the Figure 1), raw water, without previous treatment, was delivered through a column (1a on the Figure 1) that contained $1 \mathrm{~L}$ of medium Filtersorb FMH (dolomite coated with manganese dioxide, CWG GmbH, Mannheim, Germany), in order to remove iron, manganese and hydrogen sulfide, and after that was delivered through a column with Crystal Right ${ }^{\mathrm{TM}}\left(2_{\mathrm{A}}\right.$ on the Figure 1), for the removal of ammonia, in order to obtain water quality with the recommended values by Regulations for drinking water [13].

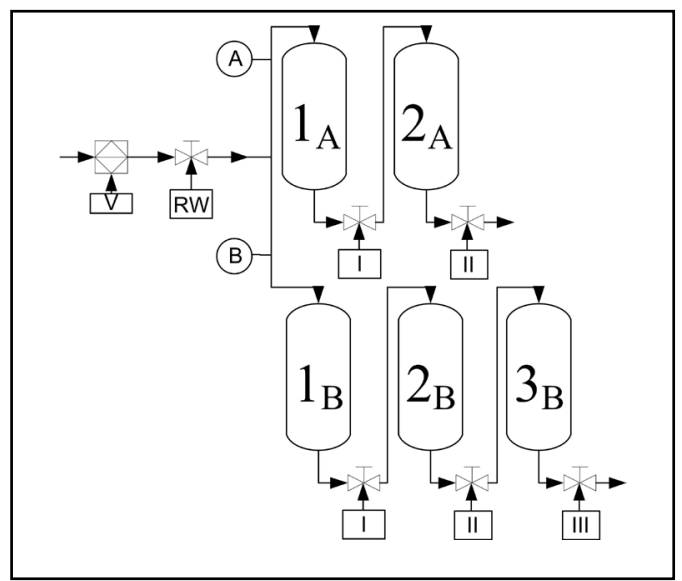

Figure 1. The chart of the experimental pilot plant. (A) The first case (when the raw water (RW) without previous treatment passes through the column filled with FMH); where are: $1_{\mathrm{A}}$-Filtersorb FMH; $2_{\mathrm{A}}$-Crystal Right ${ }^{\mathrm{TM}}$ synthetic zeolite; I, II—sampling points; (B) The second case (removal of hydrogen sulfide and ammonia, and subsequently introducing to $\mathrm{FMH}$ ); where are: $1_{\mathrm{B}}$-Lewatit MP 62; $2_{\mathrm{B}}$ - Crystal Right ${ }^{\mathrm{TM}}$ synthetic zeolite; $3_{\mathrm{B}}$-Filtersorb FMH; I, II, III-sampling points. 
In the second case (B on the Figure 1), the raw water has been flowing through a column filled with anion exchange resin Lewatit MP 62 (1b on the Figure 1) for removal of hydrogen sulfide, because it has already been tested in pilot plants [20]. After that the water was delivered through a column filled with Crystal Right ${ }^{\mathrm{TM}}\left(2_{\mathrm{B}}\right.$ on the Figure 1) for the removal of ammonia, and it would eventually be passed through a column filled with Filtersorb FMH ( $3 \mathrm{~b}$ on the Figure 1), for the removal of iron, manganese and hydrogen sulfide.

After each of the columns the outlets have been installed separately (with a Teflon valve), through which sampling of water was carried out after a certain volume of flown water (I, II, III on the Figure 1). In collected samples $\mathrm{pH}$ values were measured on the $\mathrm{pH}$ meter (pH INOLAB 730, WTW, Germany), and the concentration of hydrogen sulfide and ammonia on a spectrophotometer (Merck 60, Merck, Germany) while the concentrations of iron and manganese were determined by AAS (Aanalyst 200/400 spectrometer, Perkin Elmer USA) [21]. The obtained data of the parameters examined were statistically analyzed using basic indicators of descriptive statistics by virtue of the statistical package STATISTICA 10.0 .

\section{Results and Discussion}

For the purpose of this research raw groundwater was taken from wells with depths of $220 \mathrm{~m}$, which is characterized by increased levels of hydrogen sulfide in the range of 0.100 to $0.657 \mathrm{mg} / \mathrm{L}$, ammonia from 0.670 to 1.400 $\mathrm{mg} / \mathrm{L}$, iron of 0.820 to $1.380 \mathrm{mg} / \mathrm{L}$, manganese, from 0.048 to $0.159 \mathrm{mg} / \mathrm{L}$, while the $\mathrm{pH}$ value was in the range from 7.2 to 7.6. The chemical composition of this water is characterized by poor organoleptic properties and unpleasant odour as a consequence of the above-mentioned chemical composition of the water.

Bearing in mind the quoted specific composition of raw water, it was difficult to determine the sequence of the removal of certain pollutants in drinking water treatment. Since the usage of chemicals in the procedures for the drinking water treatment causes the formation of undesirable side products, the process of adsorption are becoming more widely represented nowadays. In the process of adsorption one of the key factors is the sequence of the removal of specific contaminants. Hydrogen sulfide, ammonia, iron and manganese are pollutants which cause interferences in the process of adsorption, influencing the adsorption capacity, in case the order of removal has not been chosen adequately. Their mutual influence was examined through the relation of the inlet and outlet concentrations of hydrogen sulfide, ammonia, iron and manganese, as a function of the volume of treated water per unit volume of the adsorption medium $\left(V_{w} / V_{a}\right.$ i.e., bead volume- $\left.B V\right)$. For the purpose of finding the sequence removal Filtersorb FMH has been used, which is commercialized in the process of drinking water treatment for removing iron, manganese and hydrogen sulfide and Crystal-Right ${ }^{\mathrm{TM}}$, synthetic zeolite for removal of ammonia and anion exchange resin (Lewatit MP 62) for removing hydrogen sulfide.

In order to explain in detail the process of removing these substances from the examined water, it is necessary to consider the adsorption processes from the point of view of adsorption equilibrium. At equilibrium a relationship exists between the concentration of the species in solution, $C$, and the "concentration" of the same species in the adsorbed state $X / M$ (i.e., the amount of species adsorbed per unit mass of adsorbent) [22]-[24]. The adsorption equilibrium relates $X / M$ to $C$. The equilibrium is a function of the temperature. The adsorption equilibrium relationship obtained at a given temperature is typically referred to as adsorption isotherm, i.e.:

$$
(X / M)=f\left(C_{e}\right)
$$

where: $x$ is the mass of the adsorbate; $M$ is the mass of the adsorbent ( $x / M$ is equilibrium concentration of adsorbable species in solid adsorbent); $C_{e}$ is an adsorbate equilibrium concentration in the solution. Since no assumption of reversible adsorption and desorption of the adsorbate molecules can be made and adsorption of mixtures of compounds on the adsorbent is very probable, in our case the removal of the adsorbate from the solution can be described by Freundlich's adsorption isotherm:

$$
(x / M)=k C_{e}^{1 / n}
$$

where: $x$ is the mass of the adsorbate; $M$ is the mass of the adsorbent $(x / M$ is equilibrium concentration of adsorbable species in solid adsorbent); $C_{e}$ is an adsorbate equilibrium concentration in the solution, $k$ and $n$ are specific adsorption coefficients ( $k$ is related to the capacity of the adsorbent, and $1 / n$ is a function of the strength of adsorption). Equation (2) can be transformed into a linear form:

$$
\log (x / M)=\log k+\frac{1}{n \log C_{e}}
$$


and approximately presented as a straight line:

$$
y=b+a x
$$

where $y$ is the ratio of organic matter concentration in treated and raw water $\left(C_{\text {eff }} / C_{\text {inf }}\right), b$ is a specific adsorption, i.e., the adsorption capacity, and $x$ is a quantity of treated water per $\mathrm{dm}^{3}$ of adsorbate. To determine the relationship between the concentration of an adsorbate in solution $(C)$ and the amount of adsorbate adsorbed per unit mass of adsorbent $(x / M)$ one can proceed with the solution being sampled and analyzed for the adsorbate. A mass balance for the adsorbate in the system is:

$$
V\left(C_{0}-C\right)=M\left[(X / M)-(X / M)_{0}\right]
$$

from which a relationship between a value of $C$ and the corresponding equilibrium value of $X / M$ canbe established. $C_{o}=C_{\text {inf }}$ is initial adsorbate concentration in solution $(\mathrm{mg} / \mathrm{L}) ;(X / M)_{o}=(X / M)_{\text {inf }}$ is initial amount of adsorbate per unit mass of adsorbent (mg/g adsorbent); $M$ is mass of adsorbent $(\mathrm{g})$ and $V$ is volume of the water in contact with the adsorbent, the Filtersorb FMH (L). In this case, virgin adsorbent was used to determine equilibrium relationship: $V(X / M)_{o}=0$, and at the beginning of the experiment, i.e. for the time $t=0$ :

$$
(X / M)_{t}=V / M\left(C_{\text {inf }}-C_{t}\right)
$$

Note that $V / M$ is the ratio between the volume of the water treated in contact with the adsorbent and the mass of the adsorbent, i.e., the value of the bed volume $(B)$ and at any time $t$ :

$$
C_{t}=C_{\text {inf }}-(M / V)\left[(X / M)_{t}\right]
$$

Equation (7) represents an operating line (from a mass balance) for the system. If the time elapsed is long enough for equilibrium to be established then this equation becomes:

$$
C_{\text {eq }}=C_{\text {eff }}=C_{\text {inf }}-(M / V)\left[(X / M)_{t}\right]
$$

In this case the long enough time is the time elapsed from the beginning of the contact of the raw water (starting concentration of the adsorbate, $C_{\text {inf }}$ ) with the adsorbent, and the time when the concentration of the adsorbate in the treated water reaches maximum allowed value, $C_{\text {eff }}$ [25] [26].

Using Equation (1) and Equation (8), one can write:

$$
\left(C_{\text {inf }}-C_{\text {eff }}\right) V / M=X / M=k C_{\text {eff }}^{1 / n}
$$

where $V / M$ is $V_{w} / V_{a}$ = bed volume. Bearing in mind the quoted adsorption processes, obtained results are represented on diagrams (Figures 2-6). Experiments have shown that the amount of material removed in a given medium in each case depends on the volume of treated water.

On the presented diagram (Figure 2), the percentage of removal of iron, manganese and hydrogen sulfide after the column Filtersorb FMH is presented (first case, A on the Figure 1). In this case, the raw water has been flowing through a column packed with Filtersorbom FMH $\left(1_{\mathrm{A}}\right)$, without prior treatment, and subsequently was delivered through a column filled with a Crystal-Right ${ }^{\mathrm{TM}}\left(2_{\mathrm{A}}\right)$, a synthetic zeolite for the removal of ammonia, in order to determine the volume of water that can be purified, and quality parameters of hydrogen sulfide, ammonia, iron and manganese fulfill recommended values by Regulations for drinking water. It is shown that the iron in the highest degree removed, in compared with other examined parameters. Therefore, saturation point of Filtersorb FMH was determined after the occurrence of iron concentration in the effluent $C_{\text {eff }}$ in the amount of $0.3 \mathrm{mg} / \mathrm{L}$ [13]. Saturation point for ammonia (behind column $2_{\mathrm{A}}$ ) was chosen for the moment when the output ammonia concentration was the same as at the entrance, at the moment when adsorption stopped.

Based on this criteria, in the first case it was found: treated water $239 \mathrm{dm}^{3}$ water/ $\mathrm{dm}^{3}$ adsorption medium was treated, up to saturation point on FMH, related to the point of saturation which is defined with concentration of $0.3 \mathrm{mg} / \mathrm{L}$ of iron in the effluent.

However, looking across the line of mean values, in this case, the concentration of manganese in the breakthrough point $\left(239 \mathrm{dm}^{3}\right)$ was about $0.137 \mathrm{mg} / \mathrm{L}$, which indicates that it is not only the manganese from the raw water $(0.100 \mathrm{mg} / \mathrm{L})$, but eluation of manganese, which is coated with Filtersorb FMH. In this case, the concentration of hydrogen sulfide observed across the line of the average value was $0.208 \mathrm{mg} / \mathrm{L}$, which represents 


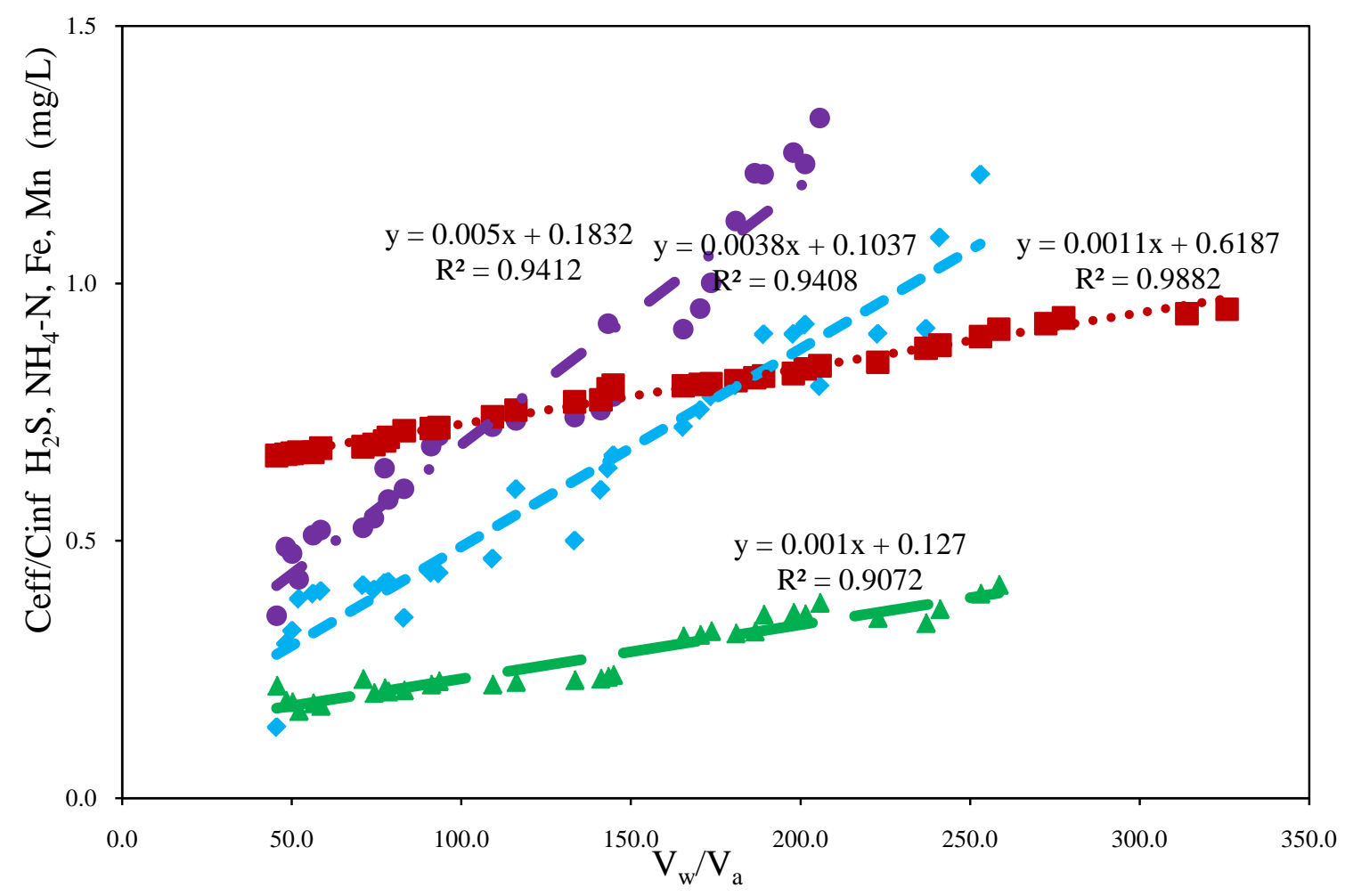

Figure 2. Average values of the hydrogen sulfide, ammonia, iron and manganese outlet and inlet concentrations ratio as a function of the volume of the treated water per adsorbate volume unit $\left(V_{w} / V_{a}=B V\right)$, case $\mathrm{A}\left(\bullet-\mathrm{H}_{2} \mathrm{~S} ; \boldsymbol{\bullet}-\mathrm{NH}_{4}-\mathrm{N} ; \boldsymbol{\Delta}-\mathrm{Fe}\right.$; - - Mn).

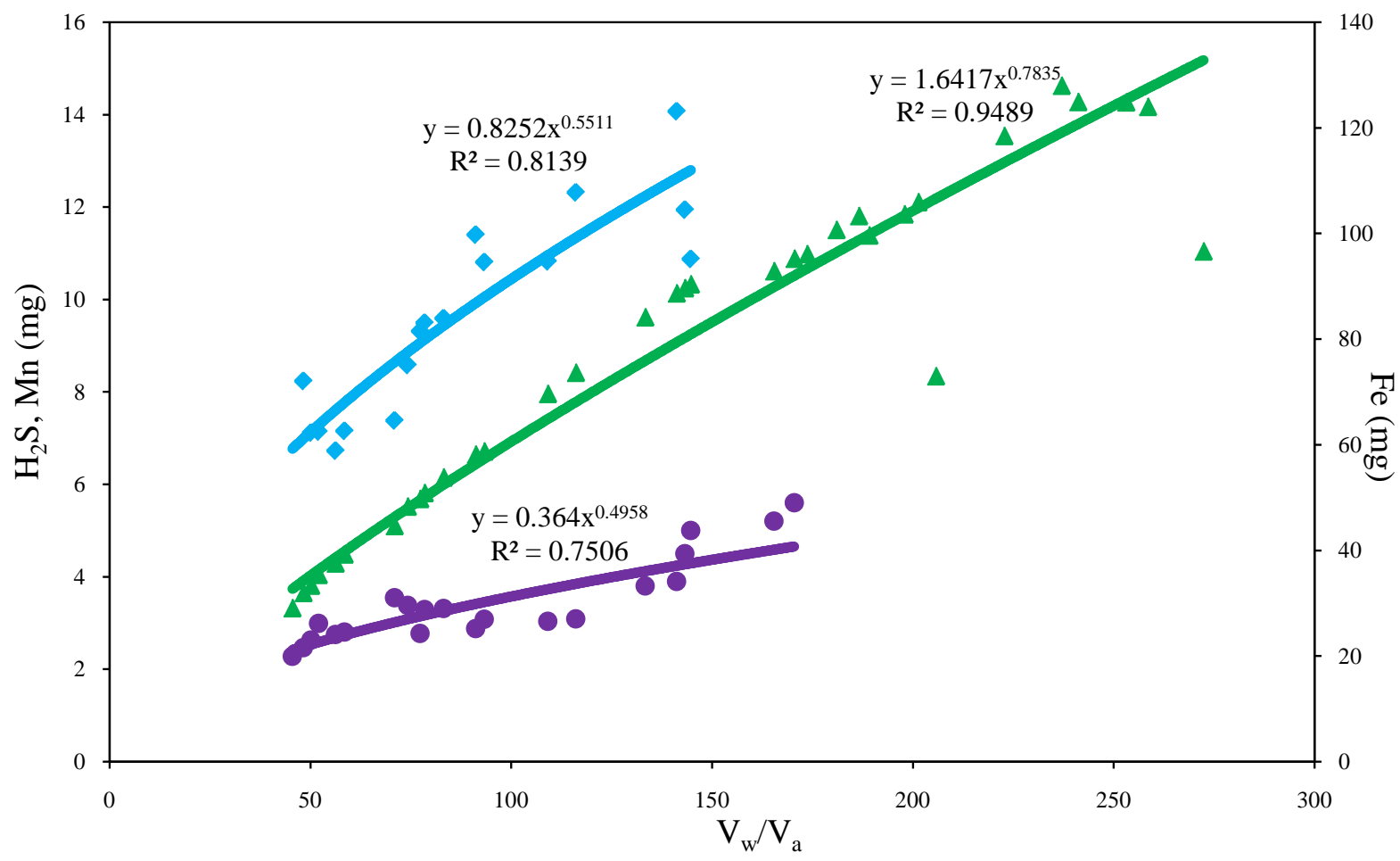

Figure 3. Average values of cumulative quantities of adsorbed hydrogen sulfide, iron and manganese as a function of the volume of treated water per adsorbate volume unit $\left(V_{w} / V_{a}=B V\right)$, case $\mathrm{A}\left(\bullet-\mathrm{H}_{2} \mathrm{~S} ; \boldsymbol{\Delta}-\mathrm{Fe} ; \bullet-\mathrm{Mn}\right)$. 


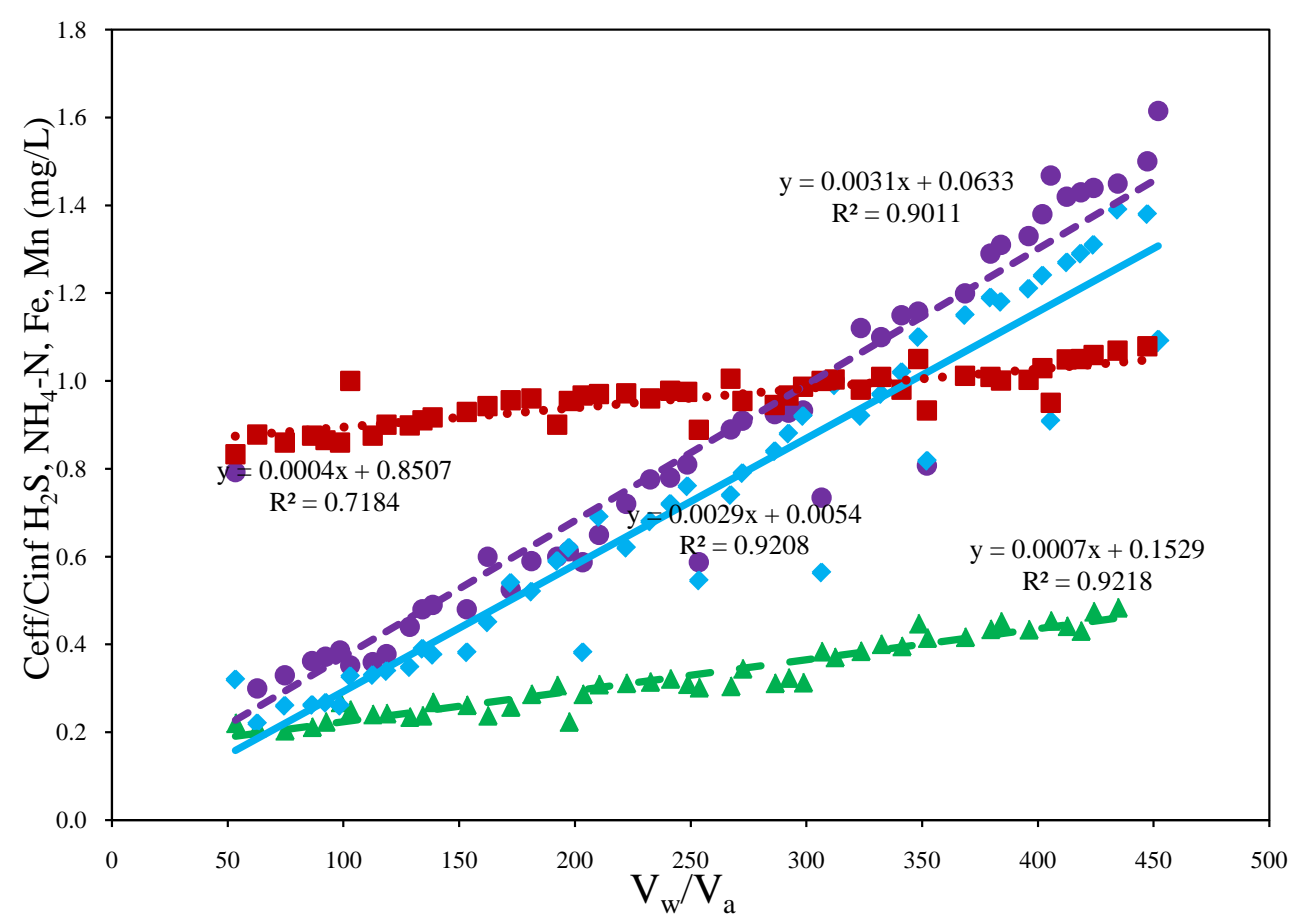

(a)

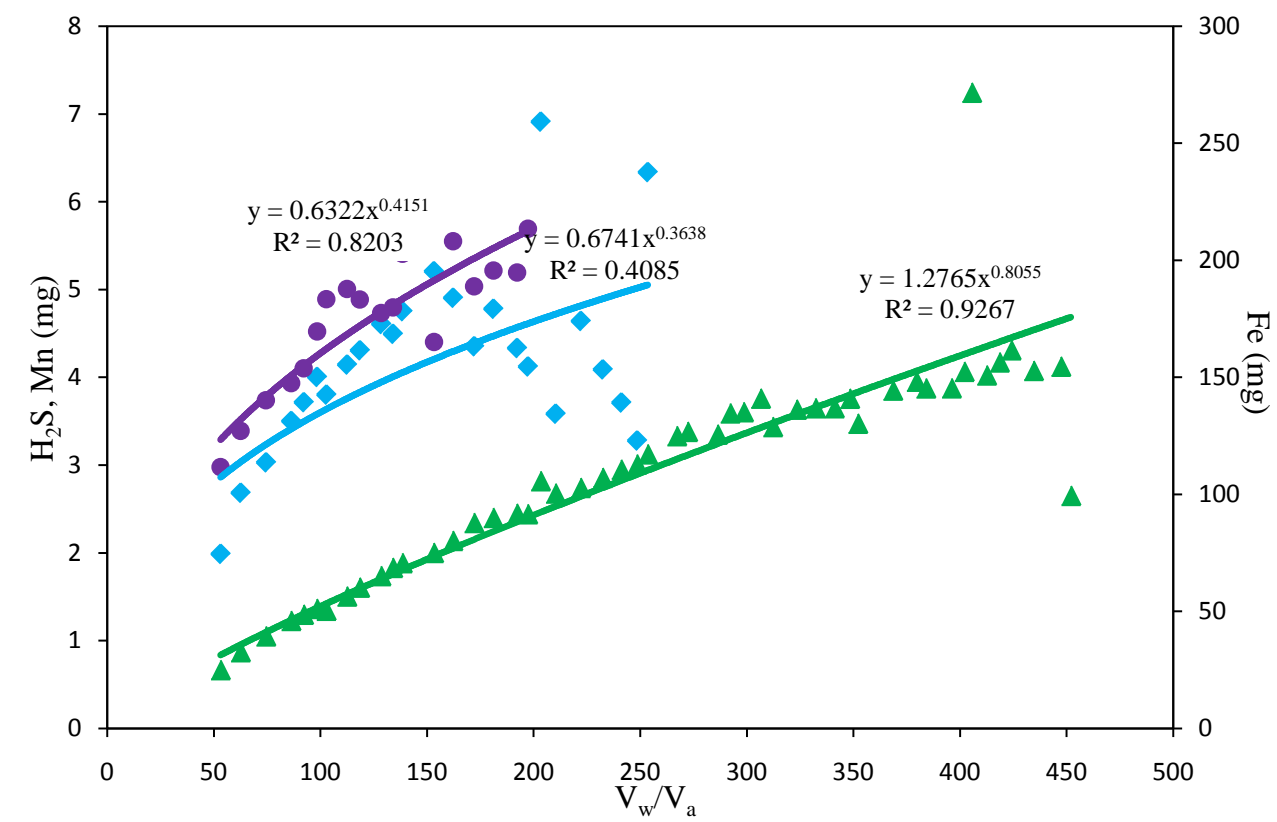

(b)

Figure 4. (a) Average values after removal of the hydrogen sulfide, ammonia, iron and manganese outlet and inlet concentrations ratio as a function of the volume of the treated water per adsorbate volume unit $\left(V_{w} / V_{a}=B V\right)$, case B $\left(-\mathrm{H}_{2} \mathrm{~S}\right.$; $-\mathrm{NH}_{4}-\mathrm{N} ; \boldsymbol{\Delta}-\mathrm{Fe}$; $\left.\bullet-\mathrm{Mn}\right)$; (b) Average values of cumulative quantities of adsorbed hydrogen sulfide, iron and manganese as a function of the volume of treated water per adsorbate volume unit $\left(V_{w} / V_{a}=B V\right)$, case B $\left(\bullet-\mathrm{H}_{2} \mathrm{~S} ; \boldsymbol{\Delta}-\mathrm{Fe} ; \bullet-\mathrm{Mn}\right)$.

equalizing inlets and outlets and the very end of the process of removing hydrogen sulfide from the raw water. On this basis, it can be concluded that the first breakthrough occurred manganese, and then it came to the breakthrough of hydrogen sulfide before it came to the point of saturation defined over iron concentration of 0.3 
$\mathrm{mg} / \mathrm{L}$. This is a very important indicator that the adsorption capacity in this medium can not be fully utilized when it comes to removing iron since it occurs well before the eluation of manganese and it undermines the quality of purified water and prevents further work.

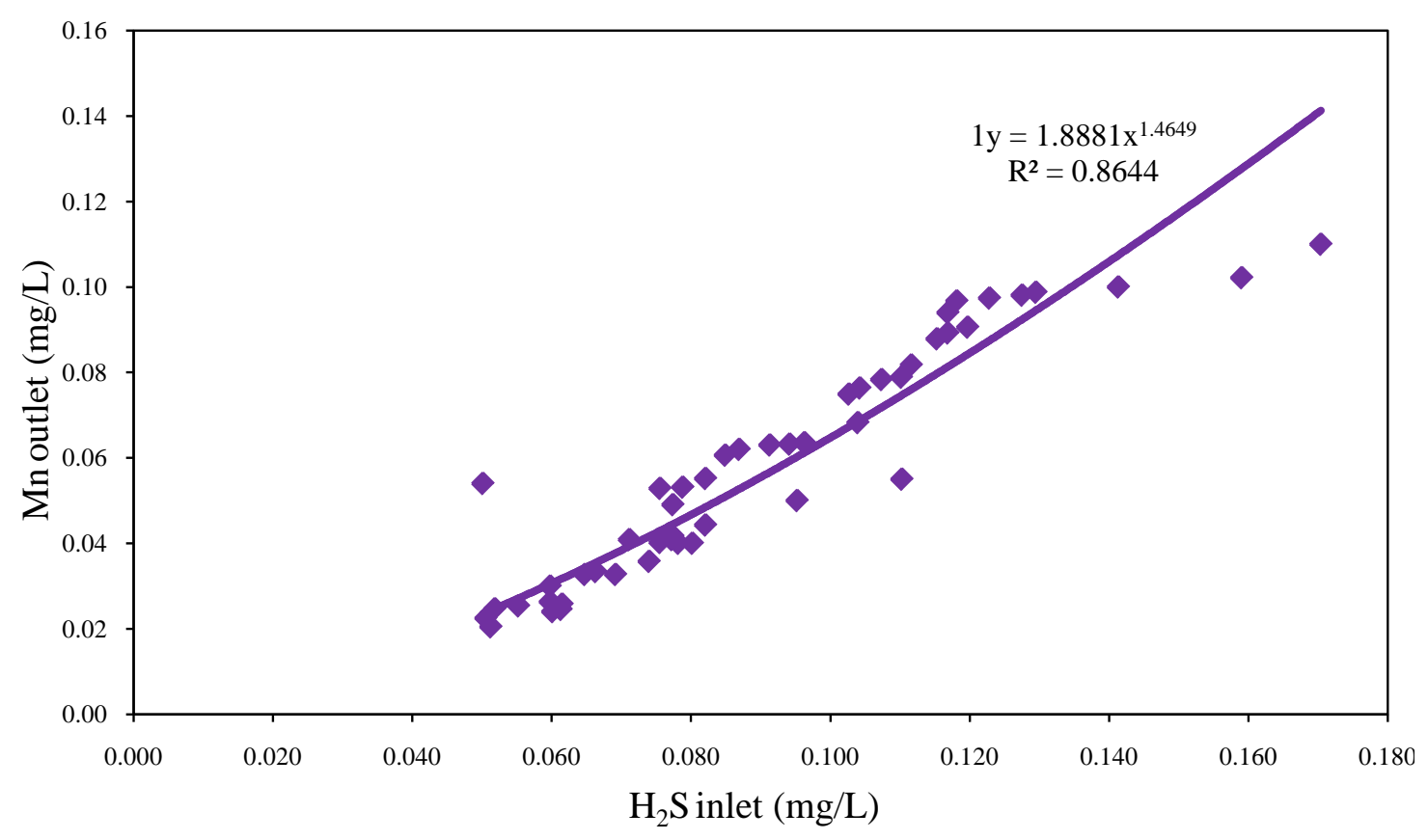

Figure 5. Comparison of manganese outlet concentration (from the Filtersorb FMH column) with hydrogen sulfide inlet concentration (from the ZEOLITE column).

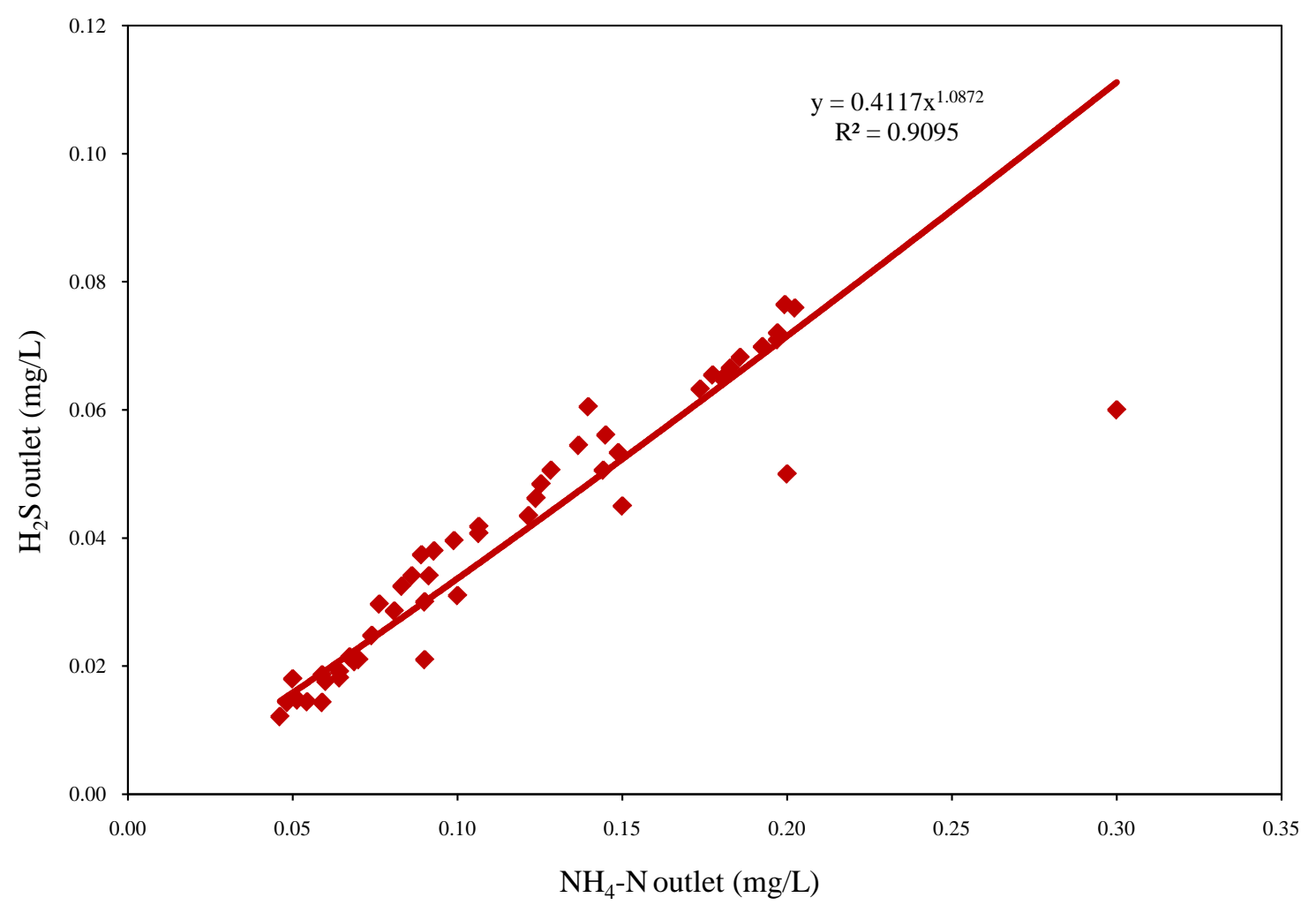

(a) 


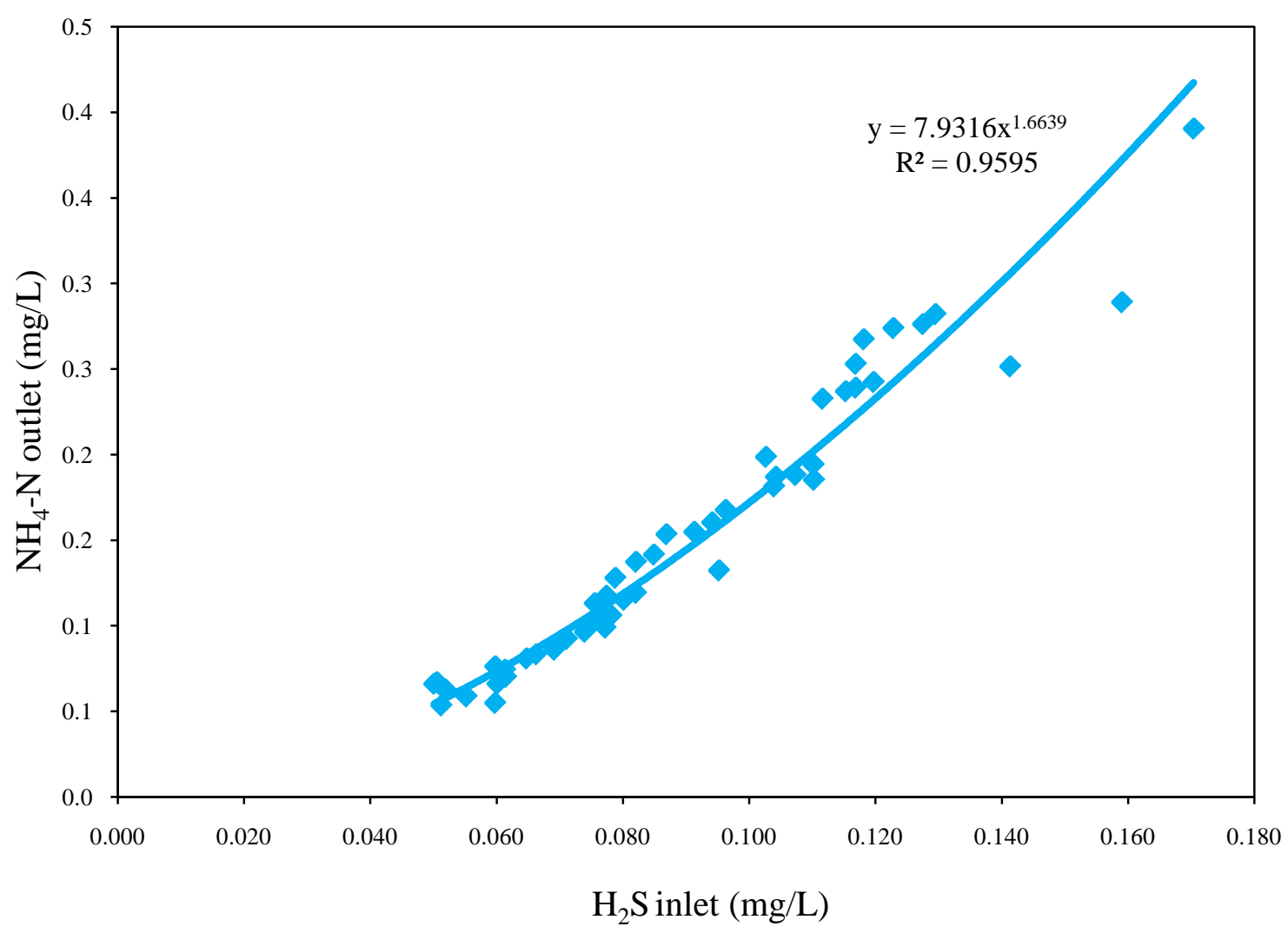

(b)

Figure 6. (a) Comparison of hydrogen sulfide outlet concentration (from the Filtersorb FMH column) with ammonia inlet concentration (from the ZEOLITE column); (b) Comparison of ammonia outlet concentration (from the Filtersorb FMH column) with hydrogen sulfide inlet concentration (from the ZEOLITE column).

Based on the observed line of the average values, it can be concluded that, at the outset of the column, the effect of the iron reduction was $87.3 \%$, and in the breakthrough point $(0.3 \mathrm{mg} / \mathrm{L})$ was $63.4 \%$. However, the percentage removal of hydrogen sulfide in the initial period was $89.6 \%$ and on the $236 \mathrm{BV}$ removal of hydrogen sulfide terminated. The percentage of manganese removal in the initial period amounted to $81.7 \%$ and at 163.4 $\mathrm{BV}$ removing of manganese was stopped. After that, the eluation of manganese occurred and manganese concentration was increased in relation to the inlet. As a result, no matter on still removing of hydrogen sulfide and iron, the process must be stopped.

The amount of each of the elements under study is presented on the Figure 3, as the cumulative amount of adsorbed matter on the medium. Following the manufacturer's specification Filtersorb FMH can remove 3000 $\mathrm{mgFe} / \mathrm{dm}^{+}$, or $1.92 \mathrm{mgFe} / \mathrm{g}$ Filtresorb FMH (spec.weight $1560 \mathrm{~g} / \mathrm{dm}^{3}$ ). Looking over $\mathrm{Mn}^{2+}$ ions, Filtersorb FMH can remove $1500 \mathrm{mgMn} / \mathrm{dm}^{3}$, or $0.96 \mathrm{mgMn} / \mathrm{g}$ Filtresorb FMH for complete capacity utilization. In the case of hydrogen sulfide adsorption, Filtersorb FMH can remove to $500 \mathrm{mg} \mathrm{H}_{2} \mathrm{~S} / \mathrm{dm}^{3}$, or $0.32 \mathrm{mgH} \mathrm{S} / \mathrm{g}$ Filtresorb FMH.

In the period up to the last $239 \mathrm{dm}^{3}$ water $/ \mathrm{dm}^{3}$ of adsorption medium, Filtersorb FMH adsorbed $119.9 \mathrm{mg}$ Fe, which means $0.076 \mathrm{mgFe} / \mathrm{g} \mathrm{FMH}$, and up to the last $163.4 \mathrm{BV}$ adsorbed $89.0 \mathrm{mg}$ Fe or $0.057 \mathrm{mgFe} / \mathrm{g} \mathrm{FMH}$. Also, up to the last $236 \mathrm{BV}$ (when removing of hydrogen sulfide was stopped), $16.8 \mathrm{mg}$ of hydrogen sulfide was adsorbed, which means $0.0107 \mathrm{mgH}_{2} \mathrm{~S} / \mathrm{g} \mathrm{FMH}$, and up to the last $163.4 \mathrm{BV}$ (when the breakthrough of manganese was occurred), $13.7 \mathrm{mg}$ of hydrogen sulfide was adsorbed, which is $0.0088 \mathrm{mgH}_{2} \mathrm{~S} / \mathrm{g}$ FMH. Up to the last flown $163.4 \mathrm{BV}, 4.55 \mathrm{mg} \mathrm{Mn}$ was adsorbed, which is $0.0029 \mathrm{mgMn} / \mathrm{g}$ FMH. After this column, the water has been flowing through a column filled with Crystal Right ${ }^{\mathrm{TM}}$ for removing of ammonia, in order to quality parameters were within the values recommended by the Regulations for drinking water. The removal of ammonia was terminated up to the past 249.6 BV, and to the past $121.0 \mathrm{BV}$, ammonia value at the outlet exceeded 0.5 $\mathrm{mg} / \mathrm{L}$ (which is recommended value by the Regulations for drinking water [13]). The cumulative effect of the ammonia removal at $121.0 \mathrm{BV}$ is $0.040 \mathrm{mg} \mathrm{NH}_{4}-\mathrm{N} / \mathrm{g}$ zeolite. The cumulative effect of removing these ele- 
ments, to the point of saturation of the effluent, indicates that in a longer period, at a constant flow, adsorption of iron occurred, and in a shorter period adsorption of hydrogen sulfide occurred, while the duration of manganese adsorption was shortest. This can be seen from the average values of the slope of the diagram line (Figure 3).

In the second case (case B on the Figure 1), the removing of the hydrogen sulfide is carried out on the anion resin (Lewatit MP62) followed by removing of the ammonia in a column filled with Crystal Right ${ }^{\mathrm{TM}}$, a synthetic zeolite for the ammonia removal, and then the water is delivered through a column filled with Filtersorb FMH. In this case, the efficiency of iron and manganese removal was analyzed, as hydrogen sulfide was removed from the raw water, so it's value at the entrance was $0.055 \mathrm{mg} / \mathrm{L}$, followed by removing of the ammonia, which value at the entrance of the column with FMH was $0.122 \mathrm{~m}^{3} / \mathrm{L}$ (Figure 4(a)).

Up to the past flown $765.2 \mathrm{BV}$ the removal of ammonia was stopped, and up to the past $503.6 \mathrm{BV}$ the value of ammonia at the outlet exceeding the $0.5 \mathrm{mg} / \mathrm{L}$. Based on the criteria when it comes to the point of saturation which is defined with iron concentration of $0.3 \mathrm{mg} / \mathrm{L}$ in the effluent, in this case it was found that up to saturation point of FMH, $410 \mathrm{dm}^{3}$ water/ $/ \mathrm{dm}^{3}$ adsorption medium was processed. Observed via line of the average values, it can be concluded that, at the very beginning of the column, the effect of reduction of iron was $84.7 \%$, while in the breakthrough point of $0.3 \mathrm{mg} / \mathrm{L}$, the effect of reduction was $56 \%$. However, the percentage of hydrogen sulfide removal, in the initial period amounted 99\%, and at $342.9 \mathrm{BV}$ removing of hydrogen sulfide was stopped. The percentage of manganese removal in the initial period was $93.7 \%$, and at $302.2 \mathrm{BV}$ removing of manganese was stopped. After the last flown $216.8 \mathrm{BV}$, values for manganese began to exceed the maximum allowable value of $0.05 \mathrm{mg} / \mathrm{L}$ [13]. After that came the eluation of manganese and because the concentration of manganese was higher than the input, the process must be stopped, no matter what it still removes iron. After that, the eluation of manganese occurred and since the manganese concentration was increased in relation to the inlet, the process must be stopped, no matter on still removing of iron. During this period, up to the last $410 \mathrm{dm}^{3}$ water $/ \mathrm{dm}^{3}$ of adsorption medium, Filtersorb FMH adsorbed $162.4 \mathrm{mg} \mathrm{Fe}$, which means $0.104 \mathrm{mgMn} / \mathrm{g} \mathrm{FMH}$, and up to the last $302.2 \mathrm{BV}, 127.0 \mathrm{mg}$ Fe was adsorbed, which is $0.081 \mathrm{MgFe} / \mathrm{g} \mathrm{FMH}$. Up to the last flown 343 $\mathrm{BV}, 5.64 \mathrm{mg}$ of hydrogen sulfide was adsorbed, which is $0.0036 \mathrm{mg} \mathrm{H}_{2} \mathrm{~S} / \mathrm{g} \mathrm{FMH}$. Up to the flown $302.2 \mathrm{BV}$, when the breakthrough point of manganese occurred, amount of $5.38 \mathrm{mg}$ of hydrogen sulfide was removed, which is $0.0034 \mathrm{mgH}_{2} \mathrm{~S} / \mathrm{g} \mathrm{FMH}$. Until the last $302.2 \mathrm{BV}, 6.77 \mathrm{mg}$ Mn adsorbed was, which is $0.0043 \mathrm{mgMn} / \mathrm{g}$ $\mathrm{FMH}$. After the last 216.8 BV (when the obtained values of manganese exceeded the maximum allowed values [13]) amount of $5.90 \mathrm{mg}$ of manganese have been removed, which is $0.0038 \mathrm{mgMn} / \mathrm{g} \mathrm{FMH}$. The cumulative effect of removing these elements, to the point of saturation of the effluent, indicates that in a longer period, at a constant flow, adsorption of iron occurred, and in a shorter period adsorption of hydrogen sulfide occurred, while the duration of manganese adsorption was shortest. This can be seen from the average values of the slope of the diagram line (Figure 4(b)).

The results showed that, in both cases, the volume of treated water directly related to the concentration of input parameters. Based on these results, it can be seen that in both cases after a certain volume of passed water, the intensively increasing of manganese concentrations began, as long as the concentration at the outlet was not equal to the concentration at the inlet, and from that moment the eluation of manganese from Filtersorb FMH began. From the standpoint of mutual competition, it was shown that the affinity of iron towards this medium was highest, while the presence of hydrogen sulfide affected the removal of manganese, and this dependence is shown in Figure 5. According to this, it can be concluded that removal of manganese during the adsorption is affected by removal of hydrogen sulfide, so it should be removed prior to the removal of manganese, and not at the same time on the same medium.

Due to the fact that adsorption is not a selective method, it was necessary to determine the relationship between the parameters, in order to establish the appropriate sequence of removal. On the basis of the inlet and outlet concentration of hydrogen sulfide from the Filtersorb FMH (Figure 6(a)) and the inlet concentration of hydrogen sulfide from the zeolite and the outlet concentration of ammonia from the Filtersorb FMH (Figure 6(b)), it was concluded that hydrogen sulfide is present in the water in the compounds where is bounded to the ammonia.

Based on the cumulative amount of adsorbed hydrogen sulfide, ammonia, iron and manganese in the second examinated case, it can be concluded that ammonia removal is followed by removing of hydrogen sulfide, which increases the volume of treated water about 2 times, in the case of the removing of manganese. Ammonia removal and simultaneously removing of hydrogen sulfide, affects the increase in the volume of treated water, also in the case of removing of iron. Although there are on the market applied commercialized products for water 
treatment for the removal of iron, manganese and hydrogen sulfide (Greensand, Greensand Plus and Filtersorb FMH), their use is difficult, because adsorption method is not selective. Thus, it is necessary to determine the appropriate sequence of removal these parameters on the specific medium or perform the multi-stage adsorption. This can be achieved, not only through the values of the electropotential, but the correlation between parameters must be determined, for the appropriate sequence of their removal. In this way, mutual interference in adsorption can be avoid, which greatly simplifies the application of commercialized media for removing of these parameters.

\section{Conclusion}

Iron, manganese, ammonia and hydrogen sulfide are pollutants that due to their values of electropotential can cause mutual interference during the adsorption, which significantly hinders the application of commercialized media for their removal. Hydrogen sulfide is a pollutant that causes problems in removing, primarily manganese during adsorption and ammonia, which is attached to it affects the volume of treated water when it comes to the removal of iron and manganese. Decrease in the concentration of hydrogen sulfide at the entrance to Filtersorb FMH for four times, has led to an increase in the volume of treated water in the amount of two times, determined by the breakthrough point of manganese. For the reason that adsorption is not selective method, for complete usage capacity of commercialized products for the removal of these pollutants, finding their mutual bond in compounds which are present in the water, is of the importance. Research has shown that the adsorption capacity cannot be sufficiently utilized unless their mutual bond in compounds is found, and appropriate sequence of removal is previously determined.

\section{Acknowledgements}

This research was supported by the Ministry of Education, Science and Technological Development of the Republic of Serbia, Project Number OI 176018.

\section{References}

[1] Okoniewska, E., Lach, J., Kacprzak, M. and Neczaj, E. (2007) The Removal of Manganese, Iron and Ammonium Nitrogen on Impregnated Activated Carbon. Desalination, 206, 251-258. http://dx.doi.org/10.1016/j.desal.2006.04.055

[2] Kontari, N. (1988) Groundwater, Iron and Manganese: An Unwelcome Trio. Water Engineering and Management, 135, 25-26.

[3] Gage, B., O’Dowd, D. and Williams, P. (2001) Biological Iron and Manganese Removal, Pilot Plant and Full Scale Application. Proceedings of the Ontario Water Works Association Conference, Ontario, 3 May 2001.

[4] World Health Organisation (WHO)-Environmental Health Criteria (EHC) (1981) 17-Manganese. World Health Organization, Geneva.

[5] World Health Organisation (WHO)-Environmental Health Criteria (EHC) (1981) 19-Hydrogen-Sulfide. World Health Organization, Geneva.

[6] World Health Organisation (WHO) (1996) Guidelines for Drinking-Water Quality, Health Criteria and Other Supporting Information. 2nd Edition, Vol. 2, World Health Organization, Geneva.

[7] Gouzinis, A., Kosmidis, N., Vayenas, D.V. and Lyberatos, G. (1998) Removal of Mn and Simultaneous Removal of $\mathrm{NH}_{3}, \mathrm{Fe}$, and Mn from Potable Water Using a Trickling Filter. Water Research, 32, 2442-2450. http://dx.doi.org/10.1016/S0043-1354(97)00471-5

[8] Tekerlekopoulou, A.G. and Vayenas, D.V. (2008) Simultaneous Biological Removal of Ammonia, Iron and Manganese from Potable Water Using a Trickling Filter. Biochemical Engineering Journal, 39, 215-220. http://dx.doi.org/10.1016/j.bej.2007.09.005

[9] Odegaard, H. (1992) Norwegian Experiences with Chemical Treatment of Raw Wastewater. Water Science and Technology, 25, 255-264.

[10] Duddles, A.G., Richardson, E.S. and Barth, I.E. (1974) Plastic Medium Trickling Filters for Biological Nitrogen Control. Journal of the Water Pollution Control Federation, 46, 937-946.

[11] Bull, R.J., Gerba, C. and Trussel, R.R. (1990) Evaluation of the Health Risks Associated with Disinfection. Critical Reviews in Environmental Control, 20, 77-114. http://dx.doi.org/10.1080/10643389009388392

[12] EEC-Drinking Water Directive (1998) Council Directive 98/83/EC. 
[13] Hygienic Standards for Drinking Water, Official Gazette of the Republic of Serbia No 42/98 and 44/99. (In Serbian)

[14] Tekerlekopoulou, A.G. and Vayenas, D.V. (2007) Ammonia, Iron and Manganese Removal from Potable Water Using Trickling Filters. Desalination, 210, 225-235. http://dx.doi.org/10.1016/j.desal.2006.05.047

[15] CWG GmbH (2008) Filter Media for Removing Iron, Manganese and Hydrogen Sulfide from Drinking and Ground Water. Filtersorb FMH-Product Information. CWG GmbH, Mannheim.

[16] Hedström, A. (2001) Ion Exchange of Ammonium in Zeolites: A Literature Review. Journal of Environmental Engineering, 127, 673-681. http://dx.doi.org/10.1061/(ASCE)0733-9372(2001)127:8(673)

[17] Mouchet, P. (1992) From Conventional to Biological Removal of Iron and Manganese in France. Journal of American Water Works Association, 84, 158-166.

[18] Frischherz, H., Zibuschka, F., Jung, H. and Zerobin, W. (1985) Biological Elimination of Iron and Manganese. Water Supply, 3, 125-136.

[19] Vandenabeele, J., De Beer, D., Germonpre, R., Van De Sande, R. and Verstraete, W. (1995) Influence of Nitrate on Manganese Removing Microbial Consortia from Sand Filters. Water Research, 29, 579-587. http://dx.doi.org/10.1016/0043-1354(94)00173-5

[20] Vidovic, M.M., Jovićević, J.N., Krstić, J.D., Tomić, I.D. and Rogan, S.S. (2010) The Influence of pH on Removal of $\mathrm{H}_{2} \mathrm{~S}$ and Natural Organic Matter by Anion Resin. Desalination and Water Treatment, 21, 255-263. http://dx.doi.org/10.5004/dwt.2010.1545

[21] APHA AWWA WEF (1995) Standard Methods for the Examination of Water and Wastewater. 19th Edition, American Public Health Association, Washington DC.

[22] Lin, J.X. and Wang, L. (2009) Adsorption of Dyes Using Magnesium Hydroxide-Modified Diatomite. Desalination and Water Treatment, 8, 263-271. http://dx.doi.org/10.5004/dwt.2009.786

[23] Khenniche, V. and Aissani, F. (2009) Characterization and Utilization of Activated Carbons Prepared from Coffee Residue for Adsorptive Removal of Salicylic Acid and Phenol: Kinetic and Isotherm Study. Desalination and Water Treatment, 11, 192-203. http://dx.doi.org/10.1061/(ASCE)0733-9372(2001)127:8(673)

[24] Fungaro, D.A., Bruno, M. and Grosche, L.C. (2009) Adsorption and Kinetic Studies of Methylene Blue on Zeolite Synthesized from Fly Ash. Desalination and Water Treatment, 2, 231-239. http://dx.doi.org/10.1061/(ASCE)0733-9372(2001)127:8(673)

[25] Bansal, R.C. and Goyal, M. (2005) Activated Carbon Adsorption from Solutions. In: Bansal, R.C. and Goyal, M., Eds., Activated Carbon Adsorption, CRC Press, Boca Raton, 145-196. http://dx.doi.org/10.1201/9781420028812.ch3

[26] Armenante, P.M. (2007) Adsorption. http://cpe.njit.edu/dlnotes/CHE685/Cls11-1.pdf 
Scientific Research Publishing (SCIRP) is one of the largest Open Access journal publishers. It is currently publishing more than 200 open access, online, peer-reviewed journals covering a wide range of academic disciplines. SCIRP serves the worldwide academic communities and contributes to the progress and application of science with its publication.

Other selected journals from SCIRP are listed as below. Submit your manuscript to us via either submit@scirp.org or Online Submission Portal.
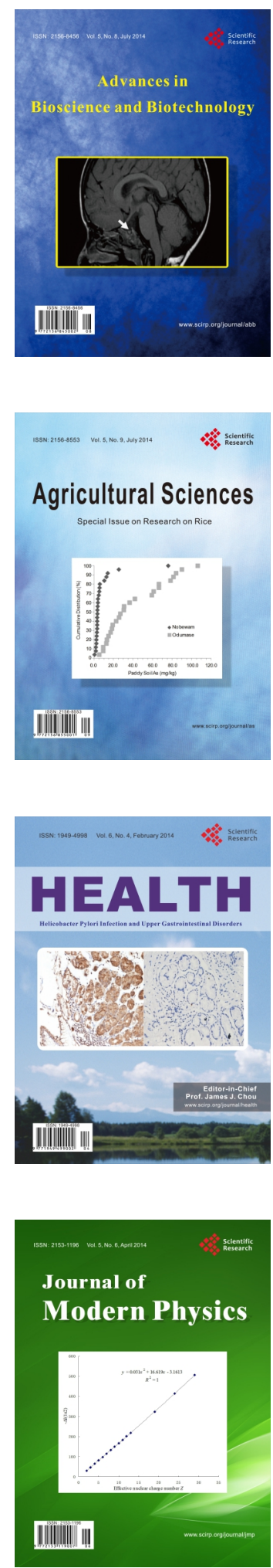
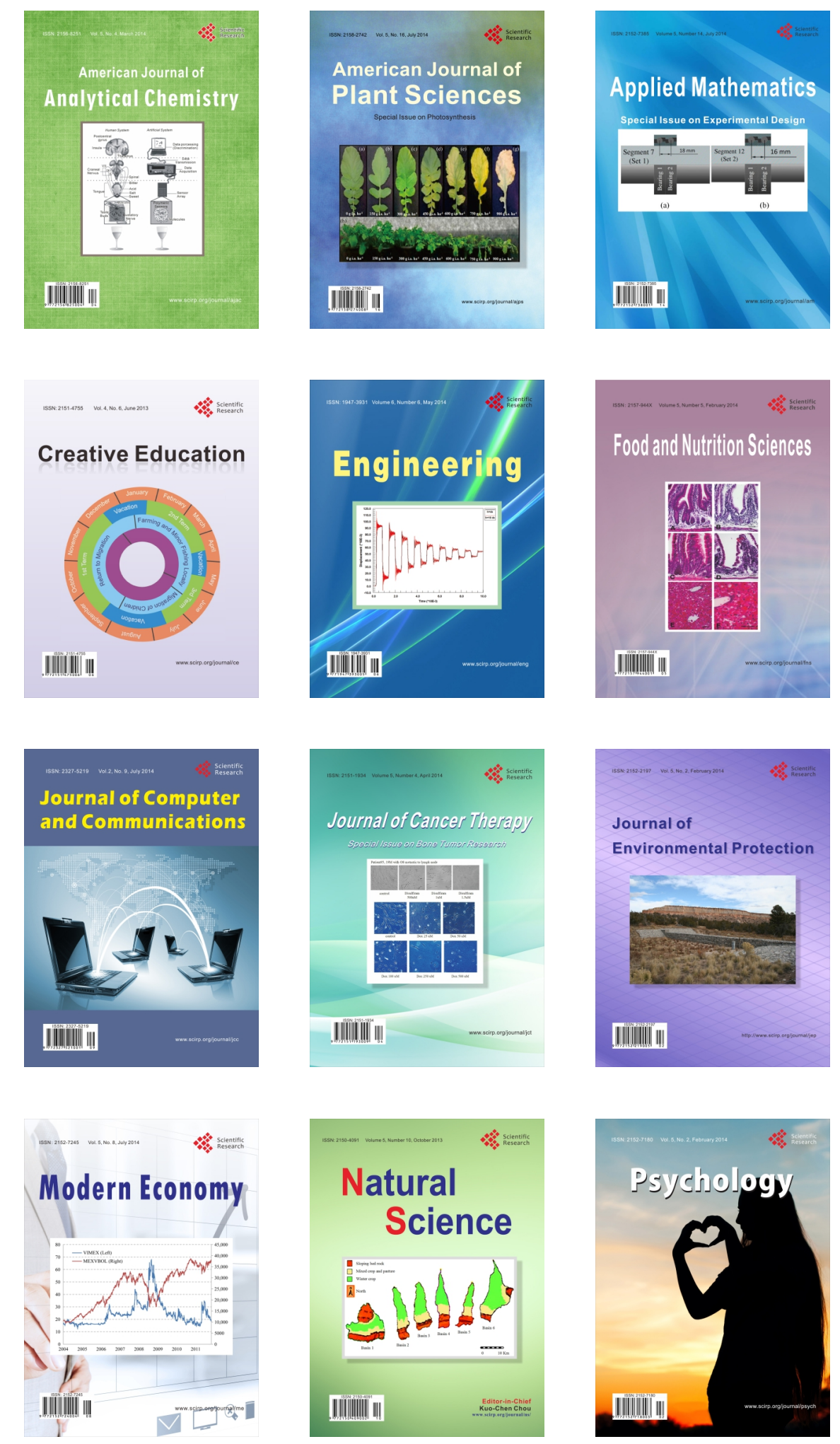